Instructions for authors, subscriptions and further details:

http://brac.hipatiapress.com

\title{
Art Games: Acción Lúdica Reflexiva
}

Ana Urroz Osés ${ }^{1}$

1) Escola Superior Politècnica, Tecnocampus. Centre adscrit a la Universitat Pompeu Fabra

Date of publication: Februery $3^{\text {rd }}, 2020$

Edition period: October 2019 - February 2020

To cite this article: Urroz, A. (2019). Art Games: Acción Lúdica Reflexiva. Barcelona, Research, Art, Creation, 8(1) 4-19. doi:

10.17583/brac.2020.3084

To link this article: http://dx.doi.org/10.17583/brac.2020.3084

PLEASE SCROLL DOWN FOR ARTICLE

The terms and conditions of use are related to the Open Journal System and to Creative Commons Attribution License (CC-BY). 
BRAC - Barcelona Research Art Creation. Vol. 8 No. 1, February 2020, pp. 4-19

\section{Art Games: Thoughtful Ludic Action}

Ana Urroz Osés

Escola Superior Politècnica, Tecnocampus. Centre adscrit a la Universitat Pompeu Fabra

(Received: 11 November 2017; Accepted: 17 January 2019; Published: 3 February 2020)

\section{Abstract}

The role of games in human social configuration has been widely researched: since the 1930s by Johan Huizinga and, later by Roger Callois in the 1950s and other authors till our days. As soon as computer science became a regular and useful tool for human endeavour, videogames appeared, playful devices created and mediated by digital technology. Ever since a group of MIT students created Spacewar in 1962, electronic gaming has been responsible for a development that has expanded in forms, technologies and purposes.

Socially, videogames constitute a popular product which is used on a massive scale and a strong industry in continuous development. In addition, there is a great diversity of genres and platforms for serious games: from educational ones and those aimed at taking care of our health or our cognitive capacity, to strategy games which purpose is to train combat personnel or to improve productivity.

In this article we will focus on the discursive and operative capabilities that net art pioneers saw in videogames, and how those operate in the art world and in social activism. We will analyse what are the traits that establish them in this scope of action, and some strategies they utilise.

Keywords: Videogames, artivism, politic, art, tactical media

2020 Hipatia Press

ISSN: 2014-8992

DOI: $10.17583 /$ brac. 2020.3084

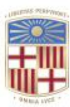

UNIVERSITAT ${ }_{\text {DE }}$ BARCELONA
Hipatia Press www.hipatiapress.com

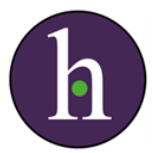


BRAC - Barcelona Research Art Creation. Vol. 8 No. 1, June 2020, pp. 4-19

\section{Art Games: Acción lúdica reflexiva}

Ana Urroz Osés

Escola Superior Politècnica, Tecnocampus Matar. Centre adscrit a la Universitat Pompeu Fabra

(Recibido: 11 noviembre 2017; Aceptado: 17 enero 2019; Publicado: 3 febrero 2020)

\section{Resumen}

El papel del juego en la configuración social humana ha sido ampliamente estudiado: desde los años 30 del siglo XX por Johan Huizinga y, posteriormente por Roger Callois en los años 50, hasta la actualidad. Cuando la informática deviene un instrumento útil y habitual en el quehacer humano, aparecen los videojuegos, aparatos lúdicos creados y mediados por tecnología digital. Desde que unos estudiantes del MIT crearan Spacewar en 1962, el juego electrónico ha protagonizado un desarrollo expandido en formas, tecnologías y objetivos.

Socialmente, los videojuegos constituyen un producto popular, de uso masivo y cuentan con una fuerte industria en continuo desarrollo. Además, existe una amplia diversidad de géneros y plataformas para los juegos electrónicos serios o formativos (serious games): desde los pedagógicos y los que nos ayudan a cuidar nuestra salud o la capacidad cognitiva, hasta juegos de estrategia cuya finalidad es formar personal de combate o mejorar la productividad.

En este artículo nos centraremos en la capacidad discursiva y operativa que los pioneros del net art vieron en los videojuegos, y en cómo éstos operan en el ámbito artístico y en el activismo social. Analizaremos cuáles son las características que lo sitúan en este ámbito de actuación, y algunas de las estrategias que utilizan.

Palabras clave: Videojuegos, artivismo, política, arte, medios tácticos

2020 Hipatia Press

ISSN: 2014-8992

DOI: $10.17583 /$ brac.2020.3084

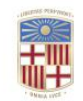

UNIVERSITAT ${ }_{\mathrm{DE}}$ BARCELONA
Hipatia Press www.hipatiapress.com 


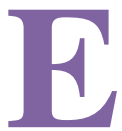

n una entrevista en El País a raíz de la inauguración de la muestra GAMEWORLD en Laboral centro de Arte y Creación de Gijón en 2007, Carl Goodman, el entonces subdirector y ahora director del Museum of the Moving Image de Nueva York explicaba la relación entre videojuegos y arte: "No es tan importante responder a la pregunta de si los videojuegos son arte o no como plantear correctamente la pregunta. ¿Puede un videojuego ser arte? La respuesta es que sí” (Lafont, 2007). Desde luego estaba considerando la posibilidad de que el creador del juego trabajara con ideas, pero también la posibilidad de que un juego pueda ser más que un mero entretenimiento. En aquel momento se comenzaba a hablar de los serious games, o juegos serios, como un formato para el aprendizaje y del desarrollo comercial a través de la gamificación:

Éste es el debate que está teniendo lugar en la industria en este momento: si hay juegos serios. Muchas personas piensan que un juego serio no es un juego porque el fin último de un juego debe ser la distracción. Los juegos serios tienen otra finalidad que no es la diversión exclusivamente. Pero eso no significa que no puedan ser entretenidos. (Lafont, 2007)

Por otra parte, artistas vinculados al net art y al activismo social hacían un uso artístico y político de las características intrínsecas del videojuego en propuestas que permitían la comprensión y la reflexión en torno a cuestiones sociales de toda índole. Estas creaciones comenzaron a aparecer a mediados de los años 90, mientras la investigación del nuevo medio, Internet, provocaba obras y proyectos artísticos activistas entre los pioneros del net art. Además de profundizar en el conocimiento del medio y sus posibilidades, utilizaron todas las técnicas y vehículos de comunicación populares o innovadores para sus fines. Y entre sus fines destacaban el conocimiento de los límites de la comunicación en línea, la investigación en nuevas narrativas disruptivas asociadas al hipertexto, la expansión de cierto espíritu crítico y propiciar la participación masiva en las obras de arte y en las acciones de carácter político.

Entre las expectativas generadas por la aparición de Internet, destaca especialmente la ilusión de democratización de la comunicación y la participación gracias al nuevo medio, y así los pioneros del net art, desde Vuk Cosic a Olia Lialina o el colectivo Electronic Disturbance Theater (EDT), desarrollaron muchas de las posibilidades entonces apenas exploradas que ahora resultan comunes en el uso social de la Red. Desde la experimentación con el hipertexto o el código ASCII de Cosic hasta las acciones de protesta 
con el software Flood Net del EDT en 1998, y por supuesto, los textos y acciones en línea del Critical Art Ensemble (CAE) que trasladaron de forma incipiente las protestas ciudadanas y la desobediencia civil al espacio virtual. Formas de comunicación, asociación y organización que años después resultaron protagonistas en movimientos sociales y grupos de activistas se vieron ya en 1999. La red de Indymedia Center se creó con ocasión de las protestas contra la reunión en Seattle del WTO en diciembre de 1999 y contra el FMI en Washington. En el año 2000 se organizó otra protesta conjunta contra las políticas del Banco Mundial, realizando manifestaciones en Praga a la vez que acciones, y en 2001 se organizaron manifestaciones en Quèbec mientras se realizaban acciones virtuales contra el Tratado de Libre Comercio FTAA.

Además de la capacidad comunicativa y el potencial activista, otro de los aspectos a investigar en aquel momento inicial era la narratividad del hipertexto, algo que Olia Lialina propone en sus primeras obras (My boyfriend come back from war, 1996). Inmediatamente, y de manera natural, se investiga y trabaja en el ámbito del videojuego, por su narrativa y su capacidad de circular y existir en línea, y porque posee características propias que lo hacen especialmente atractivo para el público potencial: es reconocible en la forma, popular como producto comercial, con una narratología específica, de uso masivo y divertido en la experiencia. Con una larga tradición de artistas comprometidos socialmente que han defendido el uso de lo lúdico para potenciar la transformación del arte y de la sociedad, los videojuegos aparecieron desde los orígenes del net art activista como obras que rompen con el carácter elitista del mercado del arte al facilitar el acceso, la participación y la conexión con el objetivo final.

Aquí trataremos de contextualizar conceptual e históricamente la aparición del videojuego artivista (arte activista), entendiendo el juego desde las teorías que lo sitúan en el origen de la cultura y la sociedad, hasta las últimas aproximaciones a una teoría del videojuego como forma cultural, pasando por las relaciones entre arte, juego y política. Finalmente, propondremos algunas de las estrategias que hacen del juego electrónico en línea un vehículo eficaz para la reflexión y el debate, tratando de conocer hasta qué punto se cumplen las expectativas de los artivistas del juego. 


\section{Homo Ludens, Homo Ludens Ludens, Homo Video Ludens. Videojuegos, Arte y Política}

A partir de la definición del Homo Ludens de Johan Huizinga Roger Callois y Vilém Flusser, y siendo testigos del auge de los videojuegos en la sociedad actual, LABoral Centro de Arte organizó en 2008 un proyecto expositivo en tres fases para investigar y analizar en profundidad la importancia y función del juego en la sociedad contemporánea. Esta trilogía del juego, Gameworld, Playware y Homo Ludens Ludens, buscaba explorar el significado y la relevancia del videojuego desde el punto de vista social y sobre todo en el ámbito del arte.

El planteamiento de Huizinga tiene el juego como origen de la cultura, y de ahí que introduzca el término Homo Ludens junto al de Homo Faber (Huizinga, 2012). Callois identifica dos polos en el jugar: la "paidia", principio invisible asociado a la diversión y la improvisación, y el "ludus" o reglas del juego arbitrarias e imperativas (Callois, 1994). Flusser, por su parte, desarrolla otra descripción de la actividad lúdica, y propone ir más allá de las reglas, considerando el jugador una suerte de dios creador: si bien las nociones de regla, acuerdo y compromiso con los otros jugadores se mantiene implícito en cualquier juego compartido, lo cierto es que el componente tecnológico que avanza Flusser, en una sociedad telemática emergente de productores de imágenes que generan información a base de jugar con el elemento técnico (Berger, 2008), lo sitúa más próximo a nuestro presente. Un presente en el que el videojuego funciona como diversión y negocio, pedagogía y salud, entrenamiento y desdoblamiento, y que fomenta la inversión en investigación y desarrollo tecnológico.

En este contexto, el simposio Homo Ludens Ludens, co-organizado por LABoral y el Planetary Collegium en 2008, recogía la herencia de los pensadores anteriores, y procuraba avanzar hacia la definición del juego en la actualidad, su relevancia social y la contextualización en relación a las diversas disciplinas que lo utilizan como estrategia,

aspirando, además, a responder a una serie de interrogantes como, por ejemplo: ¿cómo ha ido cambiando el concepto de juego y cuál es el efecto de ese cambio en el mundo de hoy?, ¿en qué medida el recurso al juego fortalece las diversas disciplinas?, ¿qué promesas, cambios y peligros traerá consigo una sociedad lúdica?, ¿podrá esa idea de la fusión de juego y vida real contribuir a una mejor comprensión de la sociedad contemporánea y sus ciudadanos? (Berger, 2008, p.18) 
En el mismo sentido, Gómez-Baeza observarla evolución del videojuego como fenómeno social por la relación que establece con la educación, su importancia en la configuración social, y "en el desarrollo del razonamiento abstracto y la percepción del individuo, las nuevas corporalidades a las que da lugar o sus posibles usos emancipatorios" (Gómez-Baeza, 2008, p. 10). Más aún, Óliver Pérez Latorre advierte de que vivimos en una sociedad del entretenimiento, en una sociedad lúdica (López Latorre, 2008). Desde la imposición en los medios del infotainment sustituyendo los informativos serios, hasta los reality shows que sustituyen las fotonovelas, la ludificación inunda y posee nuestra cultura. Ya no es sólo que los videojuegos ocupan un lugar relevante en el ocio, el consumo o el aprendizaje, ni que la gamificación constituye una suerte de estrategia empresarial ganadora, es que vivimos en una cultura lúdica: "Lo lúdico, la ludicidad, se ha convertido en un filtro cultural fundamental en nuestra forma de abordar la realidad" (López Latorre, 2008, p. 224). La importancia en número y variedad de los videojuegos, su implantación con éxito en todos los ámbitos sociales, nos convierten en una suerte de Homo Videoludens en palabras de Scolari (2013).

En nuestro caso nos centraremos en analizar los juegos electrónicos desde la ocupación del espacio del arte activista. Es decir, cómo, porqué y hasta qué punto el videojuego se convierte en un elemento social con una interfaz desde la que interactuar, que mantiene su culturalidad de producto popular pero que permite conectar nuestro mundo real/físico con el alter ego virtual que nos duplica y multiplica más allá de nuestro control. "Si admitimos la presencia masiva de esa segunda realidad virtual nos parecerá más importante aún desarrollar interfaces que nos hagan no sólo conscientes de esos encuentros a un nivel mental, sino también físico, corpóreo, sensitivo" (Stocker, 2008, p. 433). Y así, artistas que proponen reflexiones sobre cuestiones sociales adoptan el videojuego como vehículo y obra. Consiguen de esta manera la interacción del público, que pasa a ser productor/operador de la obra, incluyendo en la semántica su participación, multiplicando su significación en cuanto deja de ser obra de creador demiurgo para ser actividad colectiva. Si el contenido social es central, la participación del público/usuario completa el sentido, por activa o por pasiva. Utilizar las estrategias lúdicas y la narratología del juego digital confieren sentido, aumentan la semántica y rompen el carácter elitista de la obra acabada y aurática.

Hemos de tener en cuenta que el acto de jugar conlleva mejorar algunas habilidades a la vez que fomenta la participación y el compromiso, aspectos todos presentes en el arte interactivo. Pero no son los únicos componentes que acercan al artista activista al videojuego como elemento de enunciación y 
construcción de significado. Existe una diferencia entre el acto de jugar y el juego: mientras la acción (jugar) resulta espontánea y comporta cierto grado de alegría y diversión, el juego es un producto, un constructo diseñado con unos objetivos y reglas definidos, escenario perfecto para el acto de jugar, pero que pueden aparecer en circunstancias diferentes (elecciones, mercado de valores, las guerras) (Dragona, 2008, p. 28). En la era digital, el videojuego se ha extendido a multitud de disciplinas, y si los situacionistas propugnaban el juego como apropiación de la vida, parecería que ahora la vida adopta la forma de juego. Máxime cuando los entornos virtuales nos permiten vivir experiencias que de otra manera nos estarían vetadas.

\section{Videojuegos, Arte y Política}

\section{El juego como propuesta artística, jugar como actitud vital}

De Dadá a Fluxus, de éstos a la Internacional Situacionista, encontramos momentos en los que colectivos de artistas han propuesto el juego como eje de su discurso artístico, vinculando éste a una alternativa al modelo social imperante: el uso de la ironía, del humor, del juego de roles, de la experimentación sin cortapisas, de la diversión desbocada. El juego como espacio de desarrollo personal y social, jugar como forma de resistencia, de rebeldía, de creación. El arte como expresión, reflexión y convocatoria.

El colectivo Fluxus defendía seriamente que el arte había de ser de ser accesible, performativo, que había de independizarse del espacio museístico, perder el carácter elitista, y desmaterializarse. Concebían el arte como experiencia, no sólo para el artista, también para el público, que ha de formar parte indisoluble de la obra en tanto en cuanto la puede completar y configurar con su participación. Y en su afán por aproximar la obra al público, propiciaban que las obras se distribuyeran a bajo coste, en producciones seriadas. Esta desmitificación del arte y del artista, queda recogido en un manifiesto de Maciunas (1958) que enfrenta la idea del arte tradicional con su propuesta por el arte/juego:

El arte/juego debe ser simple, divertido, sin pretensiones, interesándose en las cosas insignificantes, no pedir ni habilidad particular ni repeticiones innumerables y no tener ningún valor mercantil o institucional. El valor del arte/juego será reducido porque será cuantitativamente ilimitado, producido en masa, accesible a todos y eventualmente producido por todos. (Maciunas, 1958) 
La propuesta subversiva de Maciunas y su grupo invitaba a la diversión, a la participación física y mental del público. Los artistas que trabajan actualmente con videojuegos recogen su herencia y se apropian del carácter popular, expansivo y experiencial de estos "divertimentos" electrónicos para resultar accesibles y disminuir el aspecto elitista de la obra de arte museística. Obras que no lo son sin la incursión del jugador/público, invitado a participar de la creación. Invitado a jugar, si bien el resultado del juego pueda no ser inocuo. En cualquier caso, invitado a formar parte de un juego desacralizado y desacralizador. Además, se apropian de las características intrínsecas de estos juegos que proponen un jugar mediado y dirigido para, desvirtuando y manipulando dichas reglas, enfrentar a jugador/público a una contradicción de tal magnitud que lo obligue a posicionarse.

En el caso de la Internacional Situacionista, la apuesta por el jugar y la diversión lúdica, más en la línea de la paidia, se plantea como revuelta, revolución y opción de vida contra la muerte que es la sociedad del espectáculo. En un ejercicio de posicionamiento político, el grupo abraza la expresión artística como vehículo de comunicación, y el vitalismo, el juego y la deriva como reapropiación de la vida.

Los artistas de Internet recogen el testigo de estos antecedentes y utilizan un medio masivo y participativo para la enunciación. Los netartistas investigan las posibilidades comunicacionales de la Red, y aprovechan todas sus características para incorporar contenido a su obra. En el caso del arte más politizado, las particularidades esenciales de la comunicación en línea se utilizan como crítica y acicate. Cuestionan el propio medio y su apropiación mercantil, a la que asisten en riguroso directo desde sus inicios en los años 90. Entre las ventajas de la Red destaca el libre acceso y la expansión global, al menos potencialmente. Al principio se constató la existencia de una brecha digital que aislaba a aquellos que no tenían acceso a Internet. Con el tiempo la brecha ha ido disminuyendo gracias a los smartphones, y la Red continúa siendo un canal de aproximación cultural, generación de contenidos y participación. Y los artivistas se valen de todos estos mecanismos para proyectar su trabajo y sus objetivos.

En el caso de los videojuegos, que generan participación masiva, posibilitan el entretenimiento, operan siguiendo unas reglas que pueden respetarse o no, y resultan de fácil comprensión, su aparición en el ámbito del arte politizado se dio desde el principio, en los años 90. Desde entonces diversos colectivos y artistas han desarrollado juegos que cuestionan el sistema social a través del entretenimiento, la paidia, y empleando el ludus 
para la reflexión, bien evidenciando la obligatoriedad del cumplimiento de las normas, bien subvirtiendo dichas leyes.

\section{Algunas tácticas y estrategias: Enmascaramiento, camuflaje, tergiversación}

Hablamos de enmascaramiento como práctica que consiste en camuflar contenidos disidentes en formas estéticas o medios de expresión dominantes, propia de los happenings y el teatro invisible. Consiste en transmitir un discurso disidente a través de las formas, gestos y estética asumidos y habituales. A su vez, se denomina camuflaje el ardid por el cual las formas del poder son imitadas para superar las barreras de comunicación de manera que permita confrontar al ciudadano con un texto o una acción que de otro modo evitarían. Estas tácticas empleadas tradicionalmente por el arte activista reaparecen con fuerza en el quehacer de artistas de Internet con intención política, y por extensión en aquellas piezas en forma de juego electrónico. Utilizando productos comerciales manipulados, o disfrazando de oficial un acto subversivo, el espectador se enfrenta a un espejo que le devuelve la imagen de un ciudadano adormecido o un sistema de control manipulador.

En algunos casos el artista se apropia del software de un videojuego ajeno pudiendo modificar los gráficos, la arquitectura, el sonido o el diseño de personajes. De hecho, la práctica de la "ingeniería inversa" está ampliamente extendida. El resultado de estos patches (alteraciones) se denominan mod (modificaciones) que se aprovechan del motor de un juego con copyrigth para parodiar su ética y/o estéticas originales, propiciando además la discusión en torno a la propiedad de los 0 y 1. En 1999, Anne-Marie Schleiner comisariaba una exposición en línea titulada "Cracking The Maze: Game Plug-ins and Patches as Hacker Art" en la que artistas y game hackers proponían obras de este tipo a partir de alterar juegos comerciales. Estas prácticas se pueden considerar una forma de tergiversación, entendiendo por tergiversación un método de distanciamiento que cambia la manera de ver objetos o imágenes generalmente conocidos, sacándolos de su contexto usual y poniéndolos en un contexto nuevo, inusual.

En el caso de los videojuegos contamos con dos elementos propios con los que actuar: la narratividad del juego y la ludología. Utilizar videojuegos como plataforma para el activismo social comienza a popularizarse con el nuevo siglo. Ya en 1999 Etoy, un grupo de artistas austro-suizos que operaban en la red, recibieron los ataques de una compañía juguetera online registrada con la URL etoys.com que pretendía quedarse con su dominio. Primero ofreció 
500.000 \$ para comprar el dominio, y ante la negativa de los artistas, presentaron una demanda judicial que sirvió para que un juez de Los Ángeles fallara en su favor y obligara a etoy.com a cerrar su sitio y dejar de usar el dominio. La respuesta de los europeos fue diseñar The Etoy Fundation Online Game, un juego online que permitía atacar simbólicamente a la compañía juguetera. Se unieron a ellos otros grupos artivistas como ${ }^{\circledR}$ TMark, The Thing, Rhizome, Nettime, l'Electronic Disturbance Theater, Hell.com y hasta un total de 1798 participantes reclutados entre diciembre de 1999 y febrero de 2000. Esta guerra de los juguetes (toywar) se basó en tácticas de Desobediencia Civil Electrónica (DCE): informar, conseguir apoyos y participantes, bombardear con correos electrónicos a empleados de eToys.com, y realizar sentadas virtuales (Baigorri, 2003).

En el juego que formularon, cada participante que se registraba se enrolaba en un ejército de soldaditos Lego, algo tan simbólico como sus propias acciones. Estos soldaditos disponían de un transmisor de radio y tenía la capacidad de enrolar más combatientes. Todas sus actividades resultaban inocuas más allá de las molestias que suponen recibir un mailing masivo o corregir una caída del servidor de la web por una sentada virtual (Denial of Service por solicitud masiva de acceso). Sin embargo, en la entonces incipiente era digital, la CNN se hizo eco de la netstrike convocada para los días 15-25 de diciembre, y las acciones de la compañía eToys.com bajaron de $67 \$$ a $31 \$$ de valor nominal. Siendo vísperas de navidad, la dificultad de efectuar compras, la campaña de disuasión y la pésima cobertura recibida de los medios en línea y fuera de línea habían contribuido a redimensionar notablemente el coloso virtual. El 29 de diciembre, Ken Ross, vicepresidente del sector de comunicaciones de eToys.com, anunciaba la voluntad de abandonar la causa "en atención a los numerosos mails recibidos que invitaban a coexistir con el grupo etoy.com".

Este es uno de los primeros ejemplos de activismo en la Red, que contaba con todos los elementos propios de la contienda social del momento, y que además tomó la forma de un juego, algo que facilitó el enganche de voluntarios. El tema era de interés candente en aquellos años, ya que la lucha por conseguir los dominios comerciales acaba de comenzar; los contrincantes representaban a la sociedad civil y a los gigantes empresariales en liza como David contra Goliath; la acción contenía y manipulaba las características comunicacionales de Internet; y la forma se parecía poderosamente a un videojuego. Todos los elementos embrionarios del posterior desarrollo de la lucha activista en la Red se daban cita en aquella propuesta. 
Así que cuando hablamos de videojuegos creados por artivistas, hablamos de camuflaje porque se valen de un medio, de un vehículo aceptado socialmente con un público amplio y convencido de antemano, y que puede ser utilizado para enunciar mensajes alternativos no sólo a la industria del juego sino a las voces del poder económico y gubernamental. Nos encontramos dos tipologías recurrentes en este tipo de proyectos artivistas, los que ofrecen el fracaso como solución única situando al jugador frente a una realidad que el ocio electrónico pretende hacer olvidar; y los que sitúan al jugador en la posición de un demiurgo con capacidad de decisión mientras le ofrece la posibilidad de reflexionar y ensayar nuevas formas de socialización.

Al realizar la obra artística/activista en forma de juego se cuenta con la ventaja del conocimiento de las convenciones al uso, ya que es un lenguaje común a un gran número de interlocutores en la Red, que conecta con los deseos de diversión de los usuarios y que al apropiarse del producto también se cuestionan las formas de mercadotecnia de las multinacionales. Tratándose de un producto lúdico habitual, su traslado al ámbito de la reflexión crítica convierte en medio táctico un soporte cotidiano. Esta cuestión facilita la comprensión y además es una forma de modificar el código sin eliminarlo. En esta línea de actuación existen numerosos proyectos que trastocan las normas del juego, que las subvierten cambiando el objetivo habitual llevándolo al fracaso y la frustración, y que proponen la identificación del jugador con un personaje perdedor cuya única posibilidad es perder en el juego, como en la vida (Baigorri, 2005). Al convertir la frustración y la pérdida en el fin de la partida, se enfrenta al usuario ante una realidad en muchos casos desconocida.

No es casual que muchas de estas propuestas de los años 90 tuvieran el Tratado de Libre Comercio México-EE.UU. como tema central, señalando las dificultades que encuentran en su camino los inmigrantes que se trasladan a Estados Unidos en busca de un futuro mejor. Para estos trabajadores que abandonan su patria, su familia y sus amigos, el camino hacia el país de las oportunidades es un continuo de arriesgadas y peligrosas situaciones hacia un hipotético final feliz. Sin embargo, como mostraba Beaner (2002), de Fran Ilich y Blas Valdez, lo que encuentran tras superar el cauce del río Grande, son las patrullas fronterizas del desierto y los peligros del "frigüey": un trabajo mal pagado y unas condiciones de vida funestas en la mayoría de los casos. Si el objetivo del juego es alcanzar la tierra de las oportunidades, una vez allí la recompensa se convierte en la frustración de una nimia victoria que no sólo trastoca las pulsiones de deseo y triunfo, sino que coloca al jugador en tierra de nadie y frente a las frustraciones diarias que tienen que ver con su situación laboral, o su concepción del mundo. Tanto Vagamundo (2002) de Ricardo 
Miranda Zuñiga, como The Maria Sisters (2003) del colectivo Global Arcade, y Crosser (2000) o La Migra (2001) de Rafael Fajardo, ahondan en este tema, colocando al jugador en el rol de un "espalda mojada" o en el de un agente fronterizo (La Migra), lo que tampoco le revierte mayores satisfacciones. Cuando la vida golpea, el juego te permite huir del dolor. Aquí, sin embargo, el éxito del juego sólo sirve para recordar la realidad.

A partir de los atentados del 11-S de 2001, las críticas a la política internacional de los EE.UU. aumentan y recrudecen. Activistas sociales y artistas que cuestionen o se oponen frontalmente a los ataques en Agfanistán encuentran en los videojuegos bélicos una plataforma enunciativa fácil de subvertir. Mientras los juegos, que en ocasiones se crean para el entrenamiento militar, ofrecen siempre la posibilidad de resultar vencedor o vencido, los juegos artivistas imposibilitan este desenlace. En AntiwarGame (2001, http://www.antiwargame.org) Josh On ofrece un anti-juego: la imposibilidad de ganar la partida en una hipotética guerra que amenaza a los Estados Unidos. El juego nos propone convertirnos en presidente de los EE.UU. y el éxito o el fracaso de nuestro personaje depende de las decisiones que tomemos en cuanto a presupuestos: a mayor presupuesto bélico y menor gasto social, menos aceptación social y viceversa. De este modo, sólo podemos ganar la guerra perdiendo aceptación popular en una suerte de paradoja irresoluble. El planteamiento del juego evidencia y hace patentes las contradicciones del sistema y coloca al jugador en el papel del presidente, teniendo que tomar las difíciles decisiones que se presentan en caso de guerra y sin posibilidad alguna de éxito.

Otra de las propuestas de mayor interés que surgieron a partir del alud de noticias relacionadas con los conflictos en Irak y Afganistán fue la aparición de los newsgames, término acuñado por Gonzalo Frasca para definir pequeños juegos o animaciones relacionadas con las noticias. Junto a un grupo de programadores crearon www.newsgaming.com para desarrollar juegos que provocaran alguna reflexión. Tratándose de uno de los principales medios de entretenimiento de nuestra época, se basan en sus códigos tergiversándolos, para evidenciar los conflictos y perversiones de nuestra sociedad. El juego September 12th (2003) nos coloca en el lugar del francotirador que tras los sucesos del 11 de septiembre de 2001 es trasladado a Afganistán o Irak. Y la función del jugador es matar guerrilleros rebeldes, aunque la recompensa se convierte en fracaso siempre, pues por cada terrorista asesinado mueren civiles cuyos familiares se convertirán en nuevos terroristas. Nunca se gana.

Cabe destacar en este breve repaso a la gestación y desarrollo de los juegos artísticos con vocación política el colectivo Molleindustria 
(http://www.molleindustria.org/). Desde su formación en 2003 producen juegos que plantean cuestiones en torno al uso de las armas (The Best Amendment, 2013), el poder y la inmunidad de las religiones mayoritarias (Operation Pedopriest, 2007), y especialmente los conflictos socio-laborales provocados por las grandes corporaciones (Every day the same dream, 2009)

La crítica a las "corporaciones" de la fe subió de tono cuando presentaron Operation Pedopriest (2007), un juego que coloca al jugador en la posición de salvar curas y monjas pederastas de ser pillados abusando de niños. Así que, en lugar de salvar a los niños, deben procurar ocultar y silenciar el delito. En definitiva, colocan luces de neón sobre el silencio cómplice, generalmente revestido de impotencia, de una sociedad que ha consentido y oculta todavía hoy el abuso de menores por parte de la curia eclesiástica.

Uno de los temas recurrentes en sus propuestas es la alienación del trabajo, la indefensión del trabajador y la impunidad de las corporaciones empresariales. Se valen del juego, del artefacto lúdico, para resaltar por contraste la deshumanización que representa el trabajo. En Every day the same dream (2009) un hombrecillo gris ejecuta monótona y lentamente las mismas acciones día tras día. Aunque el juego no dura más de 10 o 15 minutos, el ritmo de la música, la estética del juego y lo previsible del conjunto no pueden sino hacernos pensar en nuestro día a día de levantarnos, vestirnos, saludar a la familia, vecino y transeúntes, para encerrarnos en un trabajo del que no saldremos hasta el final de día. No es muy divertido como juego. No es muy divertido como vida.

Más serio y doloroso resulta el conjunto de juegos Phone Story (2011), con el que trazan un recorrido por la conflictiva cadena de creación y montaje de nuestros dispositivos electrónicos: desde las consecuencias de la extracción del coltán en el Congo, la explotación laboral en China, la contaminación de Pakistán y el consumismo descontrolado de occidente. Cada minijuego sitúa al consumidor del aparato electrónico que tiene en sus manos en la situación de evitar que descansen los maltratados mineros del Congo, o evitar el suicidio de las trabajadoras chinas. Apple prohibió su venta y lo sacó de la Apple Store después de que se hubiera aprobado 4 días antes, el 13 septiembre de 2011.

Vemos como la tergiversación y el camuflaje operan efectivamente para enfrentarnos con una realidad que se nos oculta, o nos ocultamos. Y no sólo al público. A pesar de tratarse de juegos "inocuos", que una compañía como Apple retire el juego de su tienda indica hasta qué punto evidenciar las contradicciones del sistema, en la forma y en el fondo, provocan reacciones más allá del simbolismo. Queda por determinar, en todo caso, hasta qué punto resultan efectivas estas propuestas artivistas en forma de juegos. 


\section{A modo de conclusión: Entre la simulación y la efectividad}

Si hemos visto cómo los juegos poseen la capacidad de educar, instruir, entrenar y divertir, podríamos asumir que los videojuegos artísticos activistas poseen la capacidad de hacer reflexionar al público. Cuando los artistas ocupan la Red como medio táctico y contenido de sus obras, tratan de romper con la dinámica elitista del arte entendido como "alta cultura", procurando resultar accesible e interesantes a un sector más amplio de la población. Al emplear las estrategias de los videojuegos, consiguen aumentar su atractivo y disminuir el componente elitista y críptico del arte conceptual. Sin embargo, podemos constatar algunas dificultades en el planteamiento de estos juegos. Si bien se valen de la Red como vehículo expandido, abierto y omnipresente para su difusión, también debemos recordar que la infoxicación y el carácter exclusivo del arte dificultan su acceso.

Esta contradicción en apariencia irresoluble no debería socavar el valor de unas propuestas que consiguen plantear preguntar desde nuevos ángulos, y enfrentar al espectador/participante con sus propias contradicciones. En todo caso, deberíamos considerar que existe una distancia real entre el arte, por muy activista que pretenda ser en sus objetivos conceptuales, y el activismo social. Mientras la lucha política opera y se enfrenta con el objeto que le agrede, el arte no deja de ser un operador en el terreno simbólico que no puede sustituirlo, sino en el mejor de los casos, acompañar y activar la reflexión. Decía Antoni Muntadas en una entrevista a Jaume Vidal en 2002 que el arte político cuenta con la facultad de provocar espacios para la reflexión, pero que no se puede esperar una efectividad equiparable a la acción política, sino que su sentido está en "atraer la atención, enfatizar y servir de plataforma para su reflexión" (Vidal, 2002). En un contexto en el que los videojuegos ocupan un lugar central en el espacio social-espectacular y económico-industrial, quizás lo más interesante de los videojuegos artísticos de contenido político sea que se sitúan en la estela de la célebre consigna que popularizó Jello Biafra: Don't hate the media, be the media.

\section{Referencias}

Baigorri, L. (2003). No más arte, sólo vida. 4.0. Del artivismo simulatorio a las tácticas de suplantación en la Red. Recuperado de https://www.academia.edu/9938889/No_m\%C3\%A1s_arte_s\%C3\%B 31o_vida._4.0._Del_artivismo_simulatorio_a_las_t\%C3\%A1cticas_de _suplantaci\%C3\%B3n_en_la_Red 
Baigorri, L. (2005). GAME as CRITIC as ART 3.0. Recuperado de https://www.academia.edu/20042681/Game_as_Critic_as_Art_3.0

Berger, E. (2008). Situando el juego en la cultura y sociedad contemporáneas. En: Laboral Centro de Arte y Creación industrial (ed.) Homo Ludens Ludens: Tercera entrega de la trilogía del juego. Gijón: Laboral Centro de Arte.

Callois, R. (1994). Los juegos y los hombres. La máscara y el vértigo.

México: Fondo de Cultura Económica.

Gómez-Baeza, R. (2008). Nuevos horizontes artísticos y de relación social. En Laboral Centro de Arte y Creación industrial (ed.) Homo Ludens Ludens: Tercera entrega de la trilogía del juego. Gijón: Laboral Centro de Arte.

Huizinga, J. (2012). Homo Ludens. Madrid: Alianza.

Lafont, I. (2007). Entrevista: Carl Goodman Subdirector del Museum of the Moving Image. El País. Recuperado de

https://elpais.com/diario/2007/04/05/cultura/1175724006_850215.htm 1

López Latorre, O. (2013). Apuntes sobre la teoría de la diversión. En:

Scolari, Carlos A. (ed.) Homo Videoludens 2.0. De Pacman a la gamification. (pp. 223-252). Col-lecció Transmedia XXI. Barcelona:

Laboratori de Mitjans Interactius. Universitat de Barcelona.

Maciunas, G. (1958). Manifesto on Art / Fluxus Art Amusement,

Recuperado de

http://artecontempo.blogspot.com.es/2005/06/tentativa-de-manifiestofluxus-george.html

Scolari, C. A. (ed.) (2013). Homo Videoludens 2.0. De Pacman a la gamification. Col·lecció Transmedia XXI. Barcelona: Laboratori de Mitjans Interactius. Universitat de Barcelona.

Stocker, G. (2008). Playware-Jugando a explorar la nueva realidad. En: Laboral Centro de Arte y Creación industrial (ed.) Homo Ludens Ludens: Tercera entrega de la trilogía del juego, pp. 432-433. Gijón: Laboral Centro de Arte.

Vidal, J. (2002, 28 de November). Antoni Muntadas "El arte político sólo tiene valor testimonial". El Cultural. Recuperado de https://elcultural.com/antoni-muntadas-el-arte-politico-solo-tienevalor-testimonial 
Ana Urroz Osés: Doctora en Bellas Artes.

Email address: anaurroz.grafics@gmail.com

Contact Address: Pau Gargallo, 4. 08028 Barcelona. 